\title{
Thickness of the Stationary Detonation Wave in a Mixture of Oxyhydrogen Gas with Nitrogen
}

\author{
Yu.V. Tunik, P.V. Kozlov, V.O. Mayorov \\ SRI for Mechanics, Lomonosov Moscow State University, \\ Moscow, 119192, Russia \\ vyacheslav7794@gmail.com
}

\begin{abstract}
In the experiment, the length of the detonation wave is usually determined by the duration of the luminescence of the $\mathrm{OH}$ radical, which corresponds to the zone of intense heat release. It is believed that the length of this zone is of the order of the longitudinal size of the detonation cell. In theory, the distance from the shock front of the wave to the Chapman-Jouguet point, in which the relative velocity of the gas is equal to the local speed of sound, is taken as the detonation thickness. The question arises about the possibility of introducing a coefficient of proportionality between these quantities, which would facilitate the comparison of experimental results and the theory of stationary detonation waves. This paper compares the experimental and calculated data on the length of detonation waves in mixtures of oxyhydrogen gas $\left(2 \mathrm{H}_{2}+\mathrm{O}_{2}\right)$ with nitrogen. It is shown that the introduction of the coefficient of proportionality between the length of the detonation wave and the zone of intense heat generation is impractical (see figure below).
\end{abstract}

Keywords: stationary detonation, Chapman-Jouget point, detonation wave thickness, heat release, detonation cell, sound velocity, one-dimensional approximation.

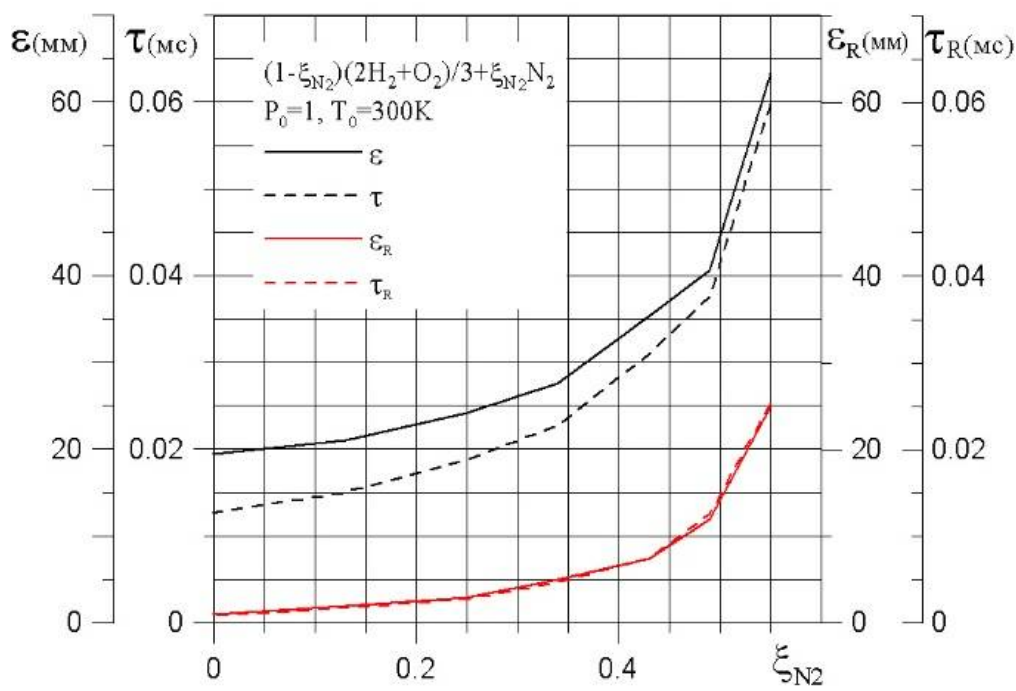

The thickness $\varepsilon$ and duration $\tau$ of detonation wave and intensive heat release zone $\left(\varepsilon_{R}\right.$ и $\left.\tau_{R}\right)$ depending on the initial molar fraction of nitrogen 


\title{
Протяженность стационарной детонационной волны в смеси гремучего газа с азотом
}

\author{
Ю.В. Туник, П.В. Козлов, В.О. Майоров \\ НИИ механики, Московский Государственный Университет им. М.В. Ломоносова, \\ Россия, Москва, 119192, Мичуринский проспект д.1 \\ vyacheslav7794@gmail.com
}

\begin{abstract}
Аннотация
В эксперименте протяженность детонационной волны обычно определяется по длительности свечения радикала $\mathrm{OH}$, что соответствует зоне интенсивного тепловыделения. Считается, что протяженность этой зоны имеет порядок продольного размера детонационной ячейки. В теории за толщину детонации принимается расстояние от ударного фронта волны до точки Чепмена-Жуге, в которой относительная скорость газа равна местной скорости звука. Возникает вопрос о возможности введения коэффициента пропорциональности между этими величинами, что облегчило бы сравнение результатов эксперимента и теории стационарных детонационных волн. В работе проводится сравнение экспериментальных и расчетных данных по протяженности детонационных волн в смесях гремучего газа $\left(2 \mathrm{H}_{2}+\mathrm{O}_{2}\right)$ с азотом. Показано, что введение коэффициента пропорциональности между протяженностью детонационной волны и зоны интенсивного тепловыделения нецелесообразно.
\end{abstract}

Ключевые слова: стационарная детонация, точка Чепмена-Жуге, толщина детонационной волны, тепловыделение, детонационная ячейка, скорость звука, одномерное приближение.

\section{1. Введение}

Самоподдерживающаяся детонация представляет собой пространственный комплекс [1-2]. Тем не менее, простые одномерные модели остаются актуальными для использования в инженерных и оценочных расчетах по эффективности детонационного горения в камерах сгорания [3-4]. Как правило, скорость детонации, рассчитанная по одномерной теории незначительно, на проценты отличается от экспериментальных данных. Модель бесконечно тонкой детонации Чепмена-Жуге оказывается полезной при анализе одиночной тройной точки спиновой детонации. Имеются попытки оценивать размер детонационной ячейки по результатам одномерных расчетов протяженности детонационной волны [5].

Самоподдерживающаяся детонация сопровождается волной разрежения. Информация о толщине зоны горения и расположении волны разрежения позволяет оценить нагрузки на стенки каналов, в которых распространяется детонационная волна. В эксперименте протяженность зоны интенсивного тепловыделения, как правило, определяется по длительности свечения радикала ОН или по пульсациям давления за ударным фронтом [6]. Поэтому ее часто принимают за продольный размер детонационной ячейки. Начальная точка волны разрежения принимается за точку Чепмена-Жуге, несмотря на то, что в случае ячеистой детонации поверхность Чепмена-Жуге становится понятием условным. В классической теории за толщину стационарной детонационной волны принимается расстояние от поверхности Чепмена-Жуге до головного ударного фронта. В экспериментах [7-9] установлено, что протяженность зоны тепловыделения, или зоны горения, в 2-4 раза меньше толщины детонационной волны. Сводные таблицы имеющихся экспериментальных данных о толщине детона- 
ционной волны и протяженности зоны горения можно найти в [6]. Однако имеющиеся сведения носят разрозненный характер.

В данной работе сравниваются расчетные и экспериментальные данные по толщине детонационной волны в гремучей смеси с азотом с тем, чтобы уточнить соотношение между этой величиной и протяженностью области горения.

\section{2. Постановка задачи и метод решения}

Считается, что детонация распространяется в невязкой смеси гремучего газа с азотом: $\left(1-\xi_{\mathrm{N} 2}\right)\left(2 \mathrm{H}_{2}+\mathrm{O}_{2}\right) / 3+\xi_{\mathrm{N} 2} \mathrm{~N}_{2}$. Структура стационарной детонационной волны рассчитывается в одномерном приближении методом установления. Используется модель ЗельдовичаНеймана-Деринга [10]. В начальный момент времени считается, что бесконечно тонкая детонация Чепмена-Жуге (БТДЧ-Ж) расположена в точке $X=0$. Перед ней $(X<0)$ давление равно одной атмосфере $\left(p=p_{0}=1\right)$, плотность $\rho_{0}$ соответствует температуре $300 \mathrm{~K}$. Скорость набегающего газа равна скорости БТДЧ-Ж, распространяющейся по покоящемуся газу. При $X>0$ задаются постоянные значения давления и плотности, которые определяются с помощью программы «Gaseq», которую можно найти в интернете в свободном доступе. Начальная скорость продуктов детонации определяется по скорости звука за БТДЧ-Ж и заданному числу Маха $\mathrm{M}>1$, что исключает влияние граничных условий на выходе из расчетной области.

Для описания процессов воспламенения и горения водорода используются детальные кинетические схемы горения [11-13]. Схема В.В. Азатяна с авторами включает девять компонент: $\mathrm{H}_{2}, \mathrm{O}_{2}, \mathrm{OH}, \mathrm{H}_{2} \mathrm{O}, \mathrm{HO}_{2}, \mathrm{H}_{2} \mathrm{O}_{2}, \mathrm{H}, \mathrm{O}, \mathrm{N}_{2}$, три реакции диссоциации и рекомбинации и шесть реакций обмена. Всего с учетом различных девяти партнеров в реакциях диссоциации - 33 реакции. Модель Ю. Варнатца с соавторами учитывает пять реакции диссоциации и четырнадцать обменных реакций. Всего 59 реакций. Термодинамические параметры смеси рассчитываются по приведенным функциям Гиббса [14] для компонент, включенных в модель горения.

Расчеты проводятся на основе модифицированной схемы С.К. Годунова второго порядка точности по пространственной переменной на гладких решениях [15]. Расчетная ячейка имеет длину 0.1 мм.

\section{3. Результаты расчетов}

Начальное распределение параметров не совпадает с точным решением для стационарной самоподдерживающейся детонации с учетом конечной скорости протекания химических реакций. Из-за этого ударный фронт начинает перемещаться. Изменение скорости движения ударного фронта носит пульсирующий характер. Выход на режим близкий к стационарному происходит за достаточно большое время, что соответствует известному решению об асимптотическом формировании самоподдерживающейся детонации в плоском случае. Полученное решение рассматривается как решение, описывающее структуру стационарной самоподдерживающейся детонации в одномерном приближении рис. 1. Здесь и ниже давление в атмосферах, расстояния и длины в миллиметрах, скорость отнесена к $U_{0}=\sqrt{p_{0} / \rho_{0}}$, время - к $t_{0}=l_{0} / U_{0}, l_{0}=1 \mathrm{Mм}$.

На рис. 2 приводится распределение молярной доли $\mathrm{OH}$, скорости звука, абсолютной и относительной скорости газа за головным ударным фронтом. Со временем происходит сближение абсолютной и относительной скорости газа. Их совпадение указывало бы на формирование стационарной детонации, распространяющейся со скоростью Чепмена-Жуге. 

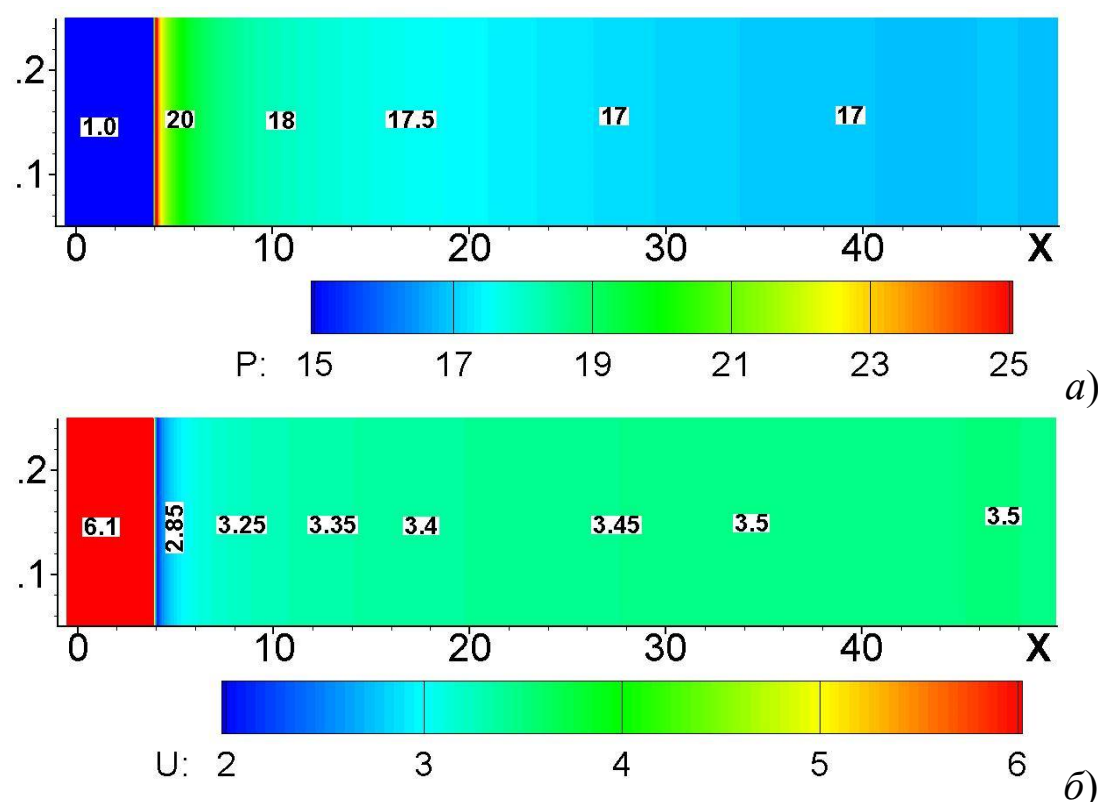

б)

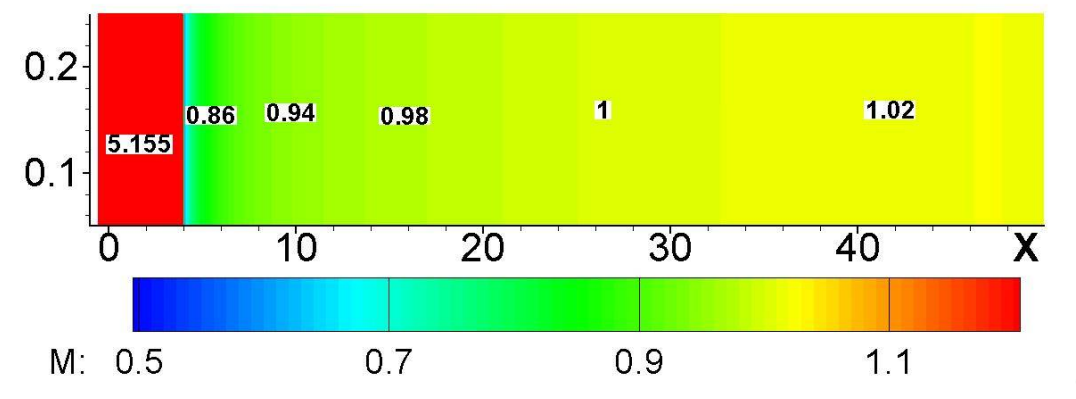

Рис. 1 Распределения параметров в потоке за ударным фронтом практически стационарной детонационной волны: $a$ ) - давление; б) - скорость газа; в) - число Маха

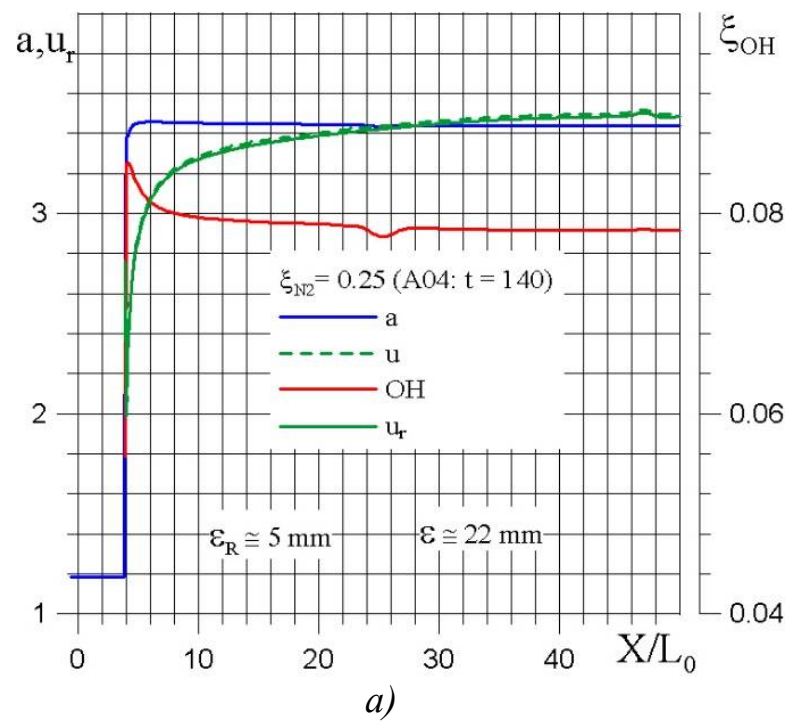

a)

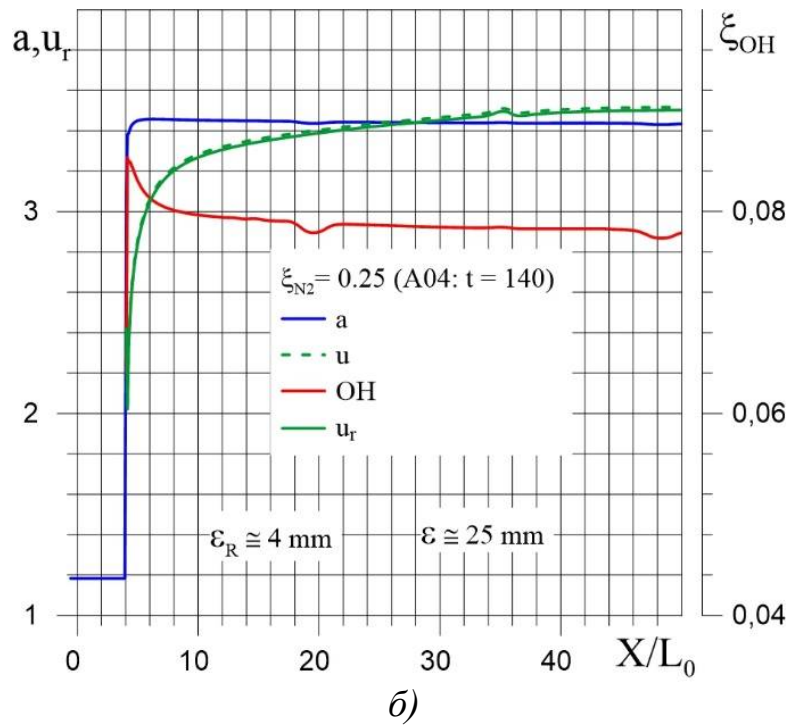

б)

Рис. 2. Зависимости абсолютной $(u)$ и относительной $\left(u_{r}\right)$ скоростей газа, звука $(a)$ и молярной доли ОН от координаты. $a$ ) - кинетическая модель Азатяна; б) - кинетическая модель Варнаца

При формировании режима близкого к стационарному это различие составляет доли процента как при использовании кинетической модели В.В.Азатяна, так и Ю.Варнатца. Протяженность детонационной волны $\varepsilon$ определяется по положению точки Чепмена-Жуге, где пересекаются кривые относительной скорости газа и скорости звука. В используемых кинетических схемах отсутствуют электронно-возбужденный радикал $\mathrm{OH}$, по свечению ко- 
торого в эксперименте определяется зона интенсивного тепловыделения. Однако считается, что их концентрация пропорциональна общей концентрации радикала. В расчетах зона интенсивного горения $\varepsilon_{R}$ начинается практически сразу за ударным фронтом и заканчивается, условно, когда концентрация радикала $\mathrm{OH}$ снижется до уровня, который на $25 \%$ выше равновесного. Для удобства сравнения с экспериментом вычисляется временная протяженность детонационной волны и зоны интенсивного тепловыделения

$$
\tau=\int_{X_{1}}^{X_{2}} \frac{\mathrm{d} x}{u_{r}}
$$

Здесь $u_{r}$ - скорость продуктов детонации относительно головного ударного фронта; $X_{1}$ и $X_{2}$ - начальная и конечная точка рассматриваемого отрезка.

На рис. 3 представлены результаты вычисления толщины детонационной волны и продолжительности зоны тепловыделения с использованием двух кинетических моделей в переменных, соответственно, длины и времени. В целом результаты близки. С увеличением концентрации азота растет протяженность детонационной волны и зоны горения, а также разница между этими величинами. Коэффициент пропорциональности между этими величинами меняется не в 2-4 раза, а на порядок. Поэтому вводить такой коэффициент для определения протяженности детонационной волны по размеру детонационной ячейки нецелесообразно.

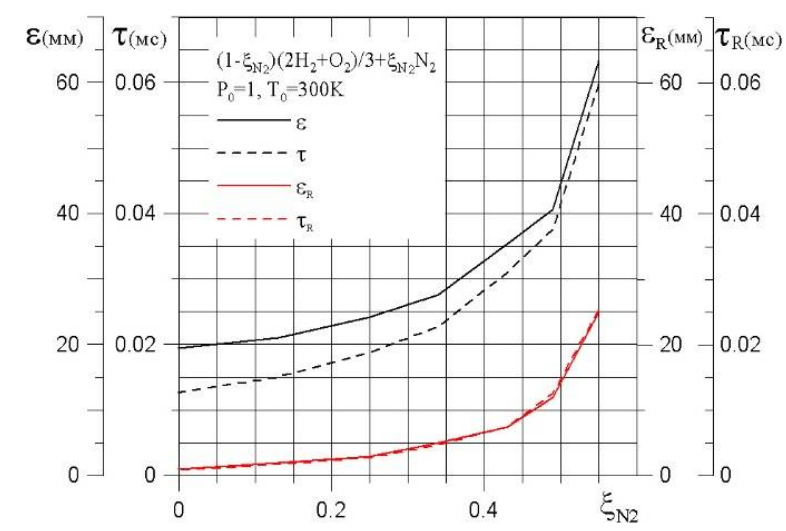

a)

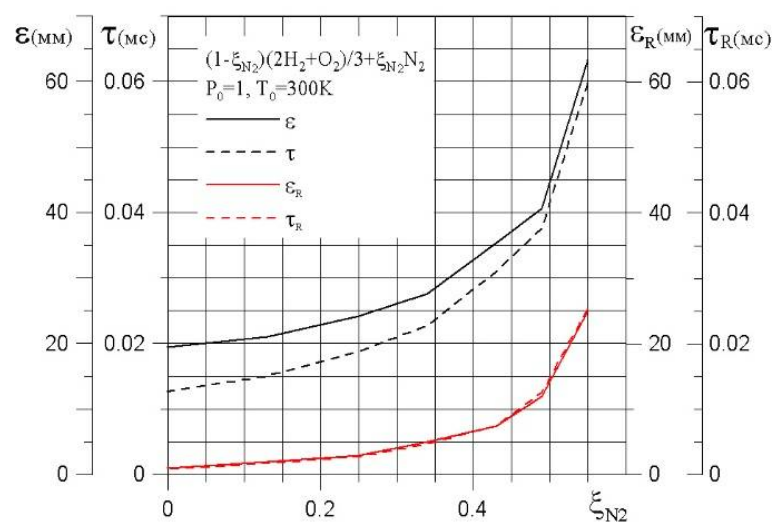

б)

Рис. 3. Толщина $\varepsilon$ и продолжительность $\tau$ детонационной волны и зоны тепловыделения ( $\varepsilon_{\mathrm{I}}$ и $\left.\tau_{\mathrm{I}}\right)$ в зависимости от начальной молярной доли азота: $a$ ) - кинетическая модель В.В. Азатяна, $\sigma$ ) - кинетическая модель Ю. Варнатца

\section{4. Сравнение с экспериментом}

Эксперименты проводятся на двухдиафрагменной ударной трубе, схема которой приведена на рис. 4. Секции изготовлены из нержавеющих труб внутренним диаметром 50 мм. Для поджога гремучей смеси, в центре глухого фланца расположен искровой промежуток (автомобильная свеча зажигания ФОРКАМ-1), через который можно осуществить наносекундный разряд керамических высоковольтных конденсаторов КВИ-3. Наносекундные времена разряда обеспечиваются тем, что конденсаторы и искровой промежуток представляют собой малоиндуктивный контур. Разряд в контуре возникает при самопробое искрового промежутка во время импульсного заряда $(300 \div 400$ мкс) керамических конденсаторов. Энергия разряда составляет порядка 100 мДж.

Вдоль камеры высокого давления располагаются пьезоэлектрические датчики давления P1 Pi6. В сечениях пьезоэлектрических датчиков P2, P3, P5 и Р5 устанавливаются приемники оптического излучения на длину волны $300 \div 320$ нм F2, F3, F5 и F5. Приемники состояли из 
УФ оптического волокна один конец, которого направляется в трубу, а излучение с другого через систему оптических фильтров поступает на ФЭУ. Временное разрешение оптической схемы менее 0.5 мкс. Между двумя секциями при высоких (более 1 атм) начальных давлениях горючей смеси устанавливается толстая разделительная перегородка из нержавеющей стали.

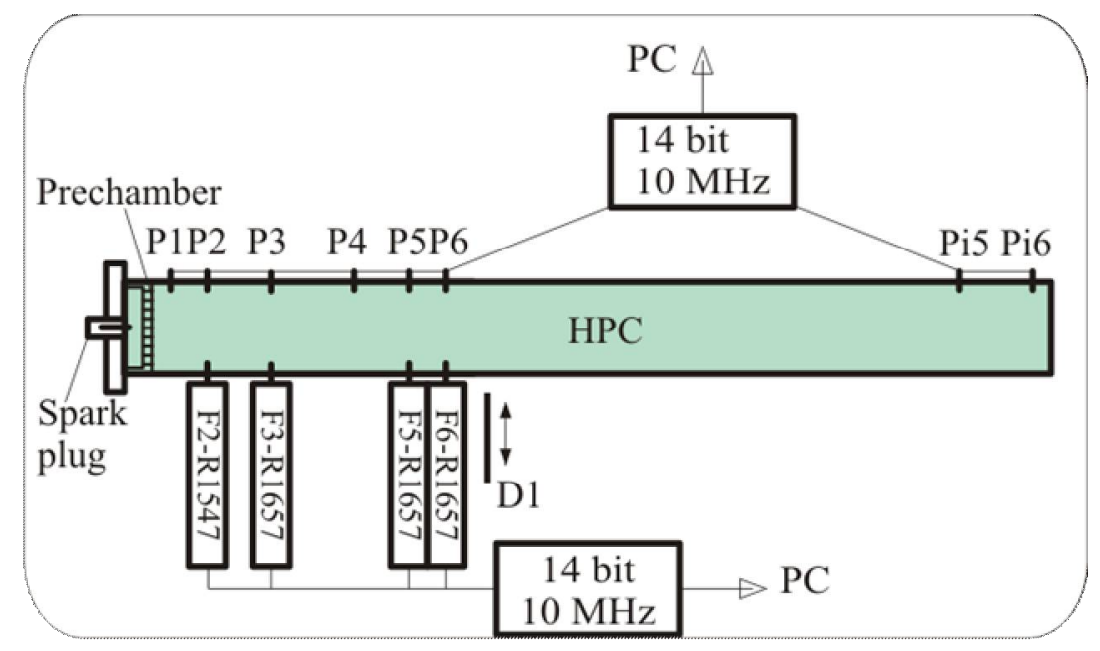

Рис. 4. Схема экспериментальной установки. Sparkplug - свеча зажигания; D1 - убираемая перегородка; цифровой запоминающий осциллограф 14 бит 2.5 МГц (Е20-10 фирмы L-CARD); P1-Pi6 - пъезодатчики; F2, F3, F5 и F6 - приемники излучения; HPC - камера сгорания; Prechamber - форкамера

В экспериментах камера заполняется стехиометрической смесью водорода с кислородом с разбавлением азотом до $50 \%$. Общее давление смеси варьируется в диапазоне $1.5 \div 5.2$ атм. Наполнение осуществляется поочередно кислородом водородом и азотом через два крана расположенных с разных сторон секции перекрытой. Перемешивание продолжается не менее часа. Более продолжительное перемешивание существенно не влияет на результаты экспериментов.

Зона тепловыделения определяется по свечению электронно-возбужденного радикала ОН. В таблице 1 приведена длительность интенсивного тепловыделения. Расчет по Кинетической модели В.В. Азатяна обеспечивает результаты близкие к экспериментальным, модель Ю. Варнатца почти вдвое занижает длительность интенсивного тепловыделения.

\section{Таблийа 1}

\section{Экспериментальные и расчетные данные по длительности тепловыделения}

\begin{tabular}{|c|c|c|c|c|}
\hline $\mathrm{N}_{2}(\%)$ & $\tau_{e}$ (мкс) эксп. & $\tau_{c}$ (мкс) Азатян & $\tau_{c}$ (мкс) Варнатц & Р (атм) \\
\hline 25 & 0.5 & 0.526 & 0.25 & 3 \\
\hline 34 & 1.0 & 0.958 & 0.34 & 4.32 \\
\hline 49 & 2.1 & 2.0 & 0.91 & 4.5 \\
\hline
\end{tabular}

\section{5. Заключение}

Численно показано, что при разбавлении гремучего газа азотом с увеличением его молярной доли от 0 до $55 \%$ толщина детонационной волны и протяженность зоны интенсивного тепловыделения ускоренно растут, соответственно, от 20 до 60 мм и от 1 до 25 мм. Используемая кинетическая модель В.В. Азатяна обеспечивает в одномерных расчетах результаты близкие к экспериментальным. Модель Ю. Варнатца почти вдвое занижает длительность интенсивного тепловыделения. 
Соотношение между толщиной зоны интенсивного тепловыделения и протяженностью детонационной волны, определяемой удаленностью точки Чепмена-Жуге от головного ударного фронта, зависит от молярной доли азота таким образом, что введение коэффициент пропорциональности между этими величинами нецелесообразно.

\section{Благодарности и ссылки на гранты}

Работа выполнена с использованием суперкомпьютера МГУ «Ломоносов».

\section{Литература}

1. Б.В. Войцеховский, В.В. Митрофанов, М.Е.Топчиян. Investigation on the structure of detonation wave in gases. $12^{\text {th }}$ International symposium on combustion. Combustion institute, Pittsburgh. 1969. P. 829.

2. Б.В. Войцеховский, Ю.Н. Денисов, В.В. Митрофанов, М.Е. Топчиян, Я.К. Трошин, К.И. Щелкин. Неустойчивость детонационных волн в газах. Бюллетень "Открытия, изобретения". 1972. № 24. Диплом № 111.

3. Kailasanath K. Review of Propulsion Applications of Detonation Waves // The American Institute of Aeronautics and Astronautics Journal. - 2000. - V. 38. - N. 9. - Pp. 1698-1708.

4. Kh. Alhussan, M. Assad, Oleq Penazkov. Analysis of the actual thermodynamic cycle of the detonation engine. Applied Thermal Engineering. 2016. V. 107. Pp. 339-344.

5. В.В. Кучинский, И.И. Оносов. Оценка размеров детонационной ячейки в газах. Журнал технической физики. 2011. Т. 81. № 6. С. 14-19.

6. М. Нетлетон. Детонация в газах.М.: Мир. 1989. 280 с.

7. Vasiliev A.A., Gavrilenko T.P., Topchian M.E. On Chapman- Jouguet surface in a multi-headed gaseous detonation. 1972. Acta Astronautica. V. 17. P. 499.

8. Edwards D.H., Jones A.T., Philips D.E. The location of the Chapman-Jouguet surface in a multiheaded detonation wave. J. Physics D. 1970. V. 9. P. 1331.

9. Bull D.C., Elsworth J.E., Shuff P.J. Metcalfe E. Detonation cell structure in fuel/air mixtures. Combustion and Flame. 1982. V. 45. Pp. 7-22.

10. Зельдович Я. Б. Теория распространения детонации в газовых системах. - ЖЭТФ, 1940, т. 10, C. 524.

11. Азатян В.В., Андрианова 3.С., Иванова А.Н. Моделирование ингибирования распространения пламени в водородовоздушной среде// Кинетика и катализ. 2010. Т. 51. № 4. С. 483-491.

12. Азатян В.В., Андрианова 3.С., Борисов А.Н., Иванова А.Н. Основные реакции, определяющие тепловыделение в процессе горения водорода с кислородом Main reactions determining heat evolution in hydrogen-oxygen combustion// Кинетика и катализ. 2012. Т. 53. № 6. С. 683-689. https://doi.org/10.1134/S002315841206002X

13. Варнатц Ю., Маас У., Диббл Р. Горение. Физические и химические аспекты, моделирование, эксперименты, образование загрязняющих веществ / Пер. с англ. Г.Л. Агафонова. Под ред. П.А. Власова. - М.: Физматлит. 2003.- 352 с. - ISBN 5-9221-0438-1.

14. Гурвич Л.В., Вейц И.В., Медведев В.А. и др. Термодинамические свойства индивидуальных веществ. Справочник. Т.1. Кн.2. М.: Наука, 1978. 327 с.

15. Туник Ю.В. Проблемы численного моделирования на основе некоторых модификаций схемы Годунова// Физико-химическая кинетика в газовой динамике. 2017. Т.18(2). http://chemphys.edu.ru/issues/2017-18-2/articles/701/ 